\title{
Use of Waste Marble Dust for Stabilization of Clayey Soil
}

\author{
Altuğ SAYGILI* \\ Muğla Sıtkı Koçman University, Department of Civil Engineering, 48000 Kötekli Campus, Muğla, Turkiye \\ cross $^{\text {ref }}$ http://dx.doi.org/10.5755/j01.ms.21.4.11966
}

Received 17 April 2015; accepted 27 July 2015

\begin{abstract}
The main objective of this research is to investigate the possibility of utilizing waste marble dust in stabilizing problematic soils (especially swelling clays). The research work was divided into two sections. The first section deals with the shear strength parameters and swelling characteristics, the second section deals with the microstructural investigation of the improved problematic soils. The marble dust addition ratios which have been studied were $0 \%, 5 \%$, $10 \%, 20 \%$ and $30 \%$ by weight. Physical, mechanical and chemical properties of soil and marble dust samples were investigated. In addition, SEM analyses were performed on the specimens. Test results indicate that marble dust addition improved the shear strength parameters and reduced the swell potential of the tested clay samples. Marble dust had a noticeable role in the hydration process because of high calcium content. Obtained results showed that marble dust addition to the clay samples will reduce the cost of constructing structures on problematic soils, and finding new utilization areas for waste marble dust will decrease environmental pollution. Utilizing waste marble dust materials in problematic soils will have great contribution to the economy and conservation of resources.

Keywords: marble dust, waste utilization, problematic soils, swelling clays, SEM, micro-structural analysis.
\end{abstract}

\section{INTRODUCTION}

Traditional materials like clay, sand, stone, gravel are being used as major materials in the highway construction and foundation works. Traditional construction materials are obtained from the existing natural resources and damage the environment due to their continuous exploitation. Nevertheless, during the process of obtaining and transporting various raw materials, high concentration polluting gases (carbon monoxide, sulfur dioxide etc.) are invariably emitted to the atmosphere by the machineries. Exposure to such toxic gases released to the environment does lead to major contamination of air, water, soil, flora, fauna, aquatic life and finally influences human health and their living conditions. Due to high transportation costs of these raw materials and environmental impacts, it is essential to find functional substitutes or partially replacement additives for traditional construction materials in the construction sector to maximize usage of byproducts. In view of the importance of energy saving and conservation of resources, efficient recycling of all solid wastes (fly ash, slag, marble dust etc.) is now a global concern requiring extensive research and development work towards exploring newer applications and maximizing use of existing technologies for a sustainable and environmentally sound management [1].

Industrial wastes (by-products) can be used solely or as admixtures so that natural sources are used more efficiently and the environment is protected from waste deposits [2]. Increasing demand for marble product in the construction industry raises the generation of waste marble dust. During the cutting process of marble blocks, the dust of the marble and water mixes together and become waste marble mud and about $25 \%$ marble is resulted in dust. In Turkey marble (natural stone) production amount was

\footnotetext{
* Corresponding author. Tel.: +90 252 2111942; fax: +90 2522111912.

E-mail address: saygili@mu.edu.tr (A. Saygili)
}

$2.7 \mathrm{Mm}^{3}$ in 2009 and Turkey has $3.8 \mathrm{Gm}^{3}$ of extractable marble reserve which is approximately $40 \%$ of the world's extractable marble reserve [2]. The marble cutting plants are dumping the waste marble powder in any nearby pit or vacant spaces near their unit, although notified areas have been marked for dumping. This leads to serious environmental and dust pollution and occupation of vast area of land.

Waste marble dust is used in different applications and purposes as a reinforcement or raw material. Most common areas and applications are brick [3], building material [4], ceramic [5] and infiltration processes [6]. Additionally, waste marble dust is used in several applications as white cement, mosaic, mortar and tile [7] and also is used in the production of clay based materials [5] and polymer modified mortars [8]. Coarse waste marble is used as filler [9] and aggregate in asphalt pavement applications [10]. Another utilization area of waste marble is the usage in clinker production [11]. Storage and handling of the unutilized waste materials, especially, in the developing countries has resulted in an increasing environmental pollution. Increasing the utilization ratio of such wastes appear to be a solution to environmental problems and will decrease the construction costs.

Okagbue and Onyebi evaluated the potential of marble dust as a stabilizing additive to red tropical soils. Parameters tested included the particle size distribution, specific gravity, Atterberg limits, the standard compaction characteristics, the compressive strength and CBR (California Bearing Ratio). After different curing conditions, plasticity reduced by $20 \%$ to $33 \%$, strength and CBR increased by $30 \%$ to $46 \%$ and $27 \%$ to $55 \%$ respectively [12].

Cai et al. investigated influence of lime and polypropylene fibre on the engineering properties of a clayey soil. Treated specimens were subjected to 
unconfined compression, direct shear, swelling and shrinkage tests. Increase in lime content resulted in a reduction of swelling and shrinkage potential. From the scanning electron microscopy analysis, it was found that use of lime produced chemical reaction between lime and soil and changed soil fabric significantly [13].

Al-Mukhtar et al. provided an explanation of improvement of geotechnical properties that arise in the expansive soil behaviour due to the lime-clay reactions, mainly a pozzolanic reaction, using microscopic analysis. The changes in the main geotechnical properties associated with the micro level texture and structure of untreated and lime-treated compacted clay samples were studied using scanning electron microscopy [14].

The purpose of this study was to investigate the usability of waste marble dust in improving problematic soils; to enhance subgrade and subbase properties, improve trafficability on construction sites and to provide volume stability. Soil stabilization using admixtures is the oldest and most widespread method of ground improvement. Cation exchange, flocculation and pozzolanic reactions are valid for stabilization of expansive soils using waste marble dust. In longterm, pozzolanic reactions occur between the calcium ions of the stabilizer (marble dust) and the silica and alumina of the clay minerals resulting in the formation of cementitious products such as calciumsilicate-hydrates (C-S-H), calcium-aluminate-hydrates (C$\mathrm{A}-\mathrm{H})$, and calciumaluminum-silicate-hydrates (C-A-S-H).

Therefore, creating new utilization areas for waste marble dust will eliminate the potentially harmful effects on environment and minimize costs due to storage. The properties investigated in this study include free swell, direct shear, unconfined compressive strength and microstructural analysis.

\section{EXPERIMENTAL DETAILS}

Kaolinite clay, bentonite clay and waste marble dust is used in this study. Grain size analysis of materials studied is given in Fig. 12. The results of the X-ray fluorescence spectrometry (XRF) chemical analysis of waste marble dust and chemical composition of the clay specimens are given in Table 1.

Table 1. Properties of clay specimens and waste marble dust

\begin{tabular}{|c|c|c|c|}
\hline Element & Kaolinite $\%$ & Bentonite $\%$ & $\begin{array}{c}\text { Waste } \\
\text { Marble Dust } \\
\%\end{array}$ \\
\hline $\mathrm{SiO}_{2}$ & 63.09 & 71.00 & 0.02300 \\
\hline $\mathrm{Al}_{2} \mathrm{O}_{3}$ & 25.50 & 14.00 & 0.00380 \\
\hline $\mathrm{TiO}_{2}$ & 0.38 & 0.05 & 0.00034 \\
\hline $\mathrm{Fe}_{2} \mathrm{O}_{3}$ & 0.37 & 0.70 & 0.00014 \\
\hline $\mathrm{CaO}$ & 0.30 & 1.10 & 55.5600 \\
\hline $\mathrm{MgO}$ & 0.01 & 3.20 & 0.26000 \\
\hline $\mathrm{Na}_{2} \mathrm{O}$ & 0.14 & 0.25 & 0.30100 \\
\hline $\mathrm{K}_{2} \mathrm{O}$ & 0.30 & 1.00 & 0.03700 \\
\hline $\mathrm{SO} O_{4}$ & 0.65 & - & - \\
\hline $\mathrm{P}_{2} \mathrm{O}$ & - & - & 0.07300 \\
\hline $\mathrm{MnO}$ & - & - & 0.00210 \\
\hline${ }^{*} \mathrm{LOI}$ & 7.30 & 10.72 & 42.48 \\
\hline *Loss on ignition & \multicolumn{3}{l}{} \\
\hline
\end{tabular}

Kaolinite and bentonite clay were supplied from a mining firm located in Çanakkale, located at the north- western part of Turkey. Waste marble dust is collected from a marble processing factory located in Yatağan, Muğla (southwestern Turkey). After collection, waste marble dust samples were ground and samples passing \#100 sieve $(0.149 \mathrm{~mm}$ opening $)$ were used in the experiments.

Three different clay mixtures are used in this study representing varied activity levels, [Type 1 (Kaolinite $70 \%$, Bentonite $30 \%$, K7B3), type 2 (Kaolinite $50 \%$, Bentonite $50 \%$, K5B5), type 3 (Kaolinite $30 \%$, Bentonite $70 \%$, K3B7), by weight]. Activity levels of tested samples increased with the rising percentage of bentonite clay in the matrix. High activity stands for large volume change when wetted and large shrinkage when dried, which possess problems in construction works. The waste marble dust was used as partial replacement of clay mixtures in the amount $(0,5,10,20,30 \%)$ by weight, presented in Table 2. Marble dust addition as partial replacement of clay decreased the activity levels from high to moderate. The samples are compacted at optimum water content within standard proctor compaction energy level (ASTM D698). Cohesion and internal friction angle variations are determined with direct shear tests (ASTM D6528), swelling potential is determined with oedometer tests. The values represented in this study are the mean value of the three replicates. After compaction, samples were wrapped and cured at $21{ }^{\circ} \mathrm{C}$ in a controlled humidity room until the test date. Samples cured for 7 and 28 days were tested for unconfined compression and direct shear test in accordance with ASTM D2166 and D6528). Samples cured for 28 and 90 days were tested for free swell test in oedometer cell in accordance with ASTM D4546. Microstructural analysis are investigated after the curing period at Mugla Sitk1 Kocman University Central Research Laboratory by using SEM (JEOL JSM-7600F). SEM is used in environmental mode. No special sample preparation (such as coating, etc.) is applied to the specimens.

Table 2. Mix proportions of test samples

\begin{tabular}{|c|c|c|c|}
\hline $\begin{array}{c}\text { Composition \% } \\
\text { Samples }\end{array}$ & Kaolinite & Bentonite & Marble Dust \\
\hline K3B7M0 & 30.00 & 70.00 & 0 \\
\hline K3B7M5 & 28.50 & 66.50 & 5 \\
\hline K3B7M10 & 27.00 & 63.00 & 10 \\
\hline K3B7M20 & 24.00 & 56.00 & 20 \\
\hline K3B7M30 & 21.00 & 49.00 & 30 \\
\hline К5B5M0 & 50.00 & 50.00 & 0 \\
\hline K5B5M5 & 47.50 & 47.50 & 5 \\
\hline K5B5M10 & 45.00 & 45.00 & 10 \\
\hline K5B5M20 & 40.00 & 40.00 & 20 \\
\hline K5B5M30 & 35.00 & 35.00 & 30 \\
\hline K7B3M0 & 70.00 & 30.00 & 0 \\
\hline K7B3M5 & 66.50 & 28.50 & 5 \\
\hline K7B3M10 & 63.00 & 27.00 & 10 \\
\hline K7B3M20 & 56.00 & 24.00 & 20 \\
\hline K7B3M30 & 49.00 & 21.00 & 30 \\
\hline
\end{tabular}

\section{RESULTS}

The optimum moisture content of the samples differed between 16.5 and $15.5 \%$, decreasing with the addition of marble dust percentage. Maximum dry unit weight values varied between 17.1 and $18.0 \mathrm{kN} / \mathrm{m}^{3}$, increasing with the 
rising percentage of marble dust addition. Samples cured for 7 and 28 days are subjected to unconfined compression tests, results are shown in Fig. 1 and Fig. 2.

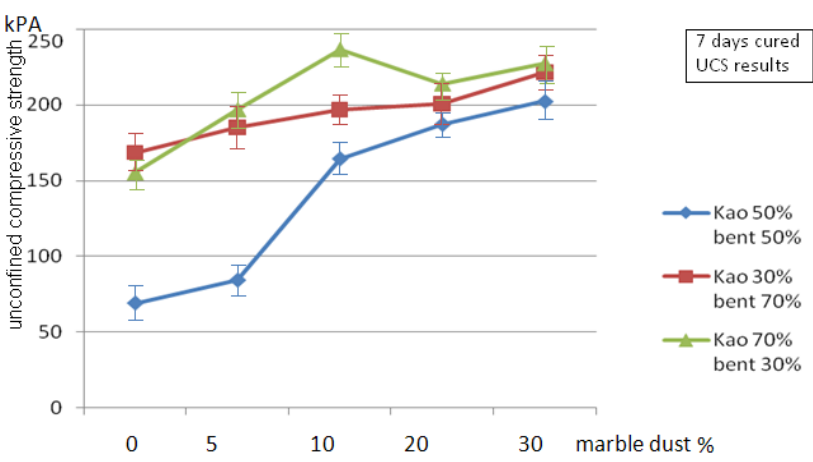

Fig. 1. 7 days cured samples unconfined compressive test results

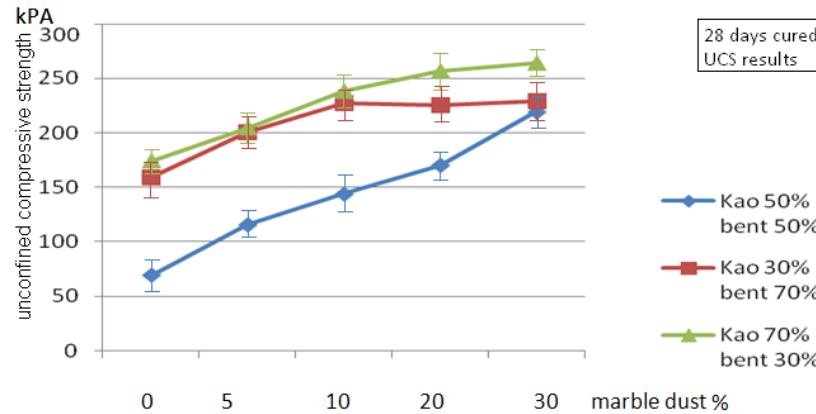

Fig. 2. 28 days cured samples unconfined compressive test results

Waste marble dust addition increased the unconfined compressive strength values of clay samples. As seen from Fig. 3 and Fig. 4, increasing waste marble dust percentage decreased the swelling potential of the tested clay specimens. The high performance of stabilized samples with waste marble dust will decrease the swelling problems of highly swelling (active) bentonite clays especially at high marble dust contents and long curing periods. As seen in Fig. 5 and Fig. 6, samples cured for 7 and 28 days are subjected to direct shear tests (applied normal forces are 20, 40 and $80 \mathrm{kPA}$ ) and internal friction angles increased with increasing waste marble dust ratio in the matrix. Within the conducted physical tests as described above, waste marble dust addition showed superior performance in problematic soils with the help of cation exchange reaction. Excess $\mathrm{Ca} 2+$ ions supplied by waste marble dust addition to the matrix, replaced cations of other elements present in the problematic soil.

Tested samples are analyzed in SEM (Scanning Electron Microscopy), EDS (Energy-dispersive X-ray spectroscopy) and achieved physical improvement is examined from the microstructural perspective (Fig. 7, Fig. 8 and Fig. 9). As seen in the SEM images and EDS results, with increasing curing time and waste marble powder percentage, voids are filled with newly composed cementitious minerals with pozzolanic reactions with the help of high calcium content in waste marble dust (Fig. 10). Observed images support the improved performance of stabilized clay samples. From SEM images, EDS and test results, it can be seen that obtained performance increase is higher than the added amount of waste marble dust percentage which shows non-plastic behavior. Therefore, improved performance of stabilized clays due to pozzolanic reactions and new cementitious mineral formation is significant (Fig. 10).

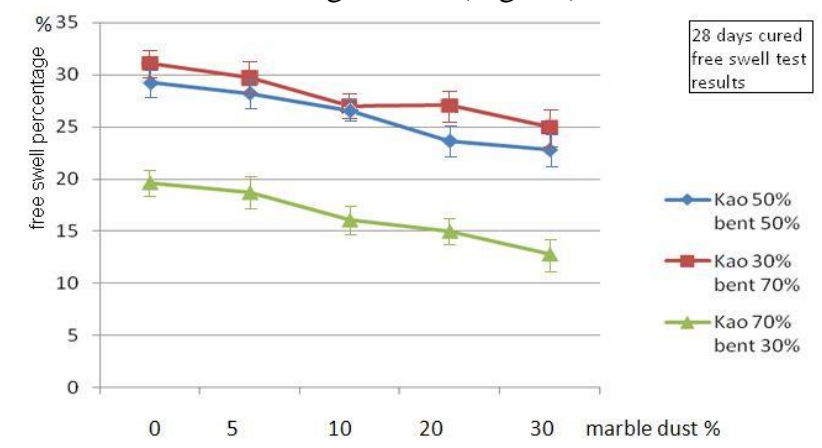

Fig. 3. 28 days cured free swell test results

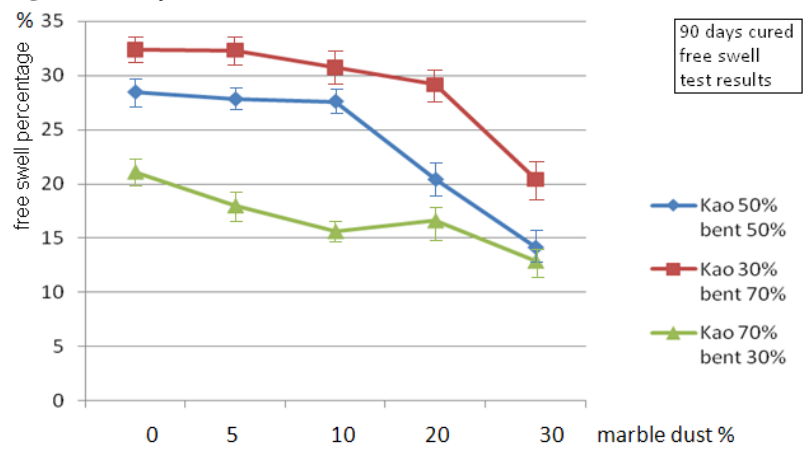

Fig. 4. 90 days cured free swell test results

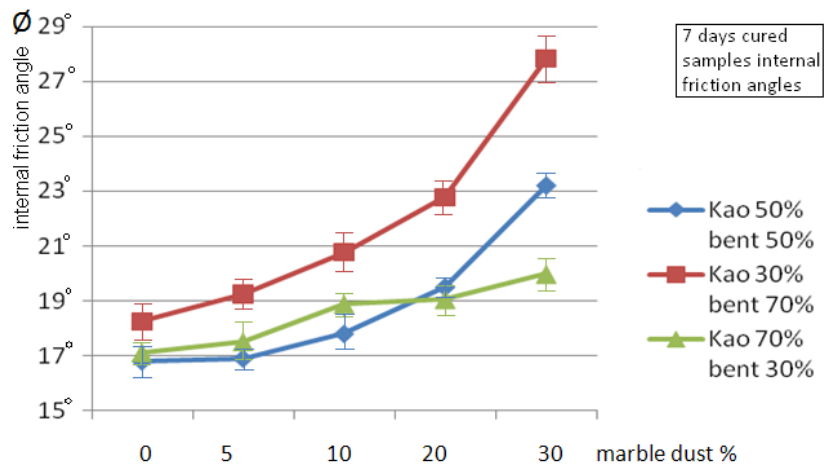

Fig. 5. 7 days cured samples internal friction angles

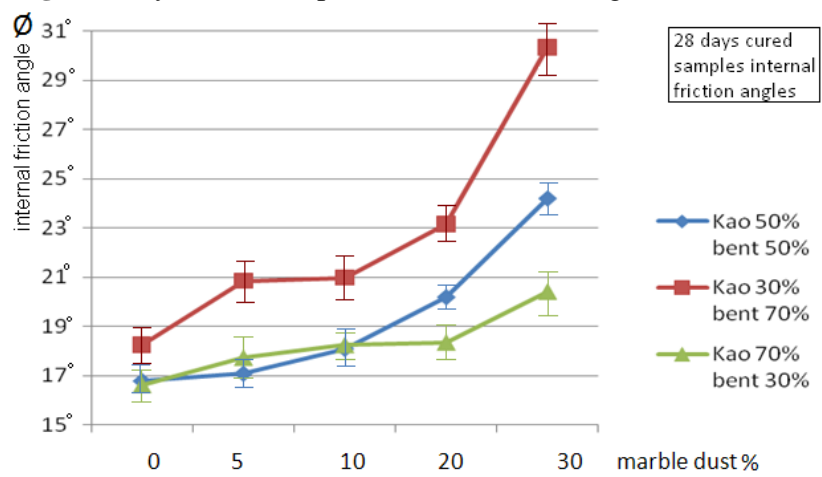

Fig. 6. 28 days cured samples internal friction angles

With curing time, shear strength parameters increase for the treated samples as the ongoing marble dust-clay reaction modifies the pore size distribution by cementation and filling them with cementitious products. Scanning electron microscopy allows us to observe the effect of improvement on morphological structure. SEM images of untreated, 10 and $20 \%$ marble dust treated (Fig. 7, Fig. 8 and Fig. 9) clay samples at scale $(5 \mu \mathrm{m})$ show very different faces (size, homogeneity) and holes (size, pores 
open or closed). The marble dust addition strongly modifies the clay texture at the micrometer scale.

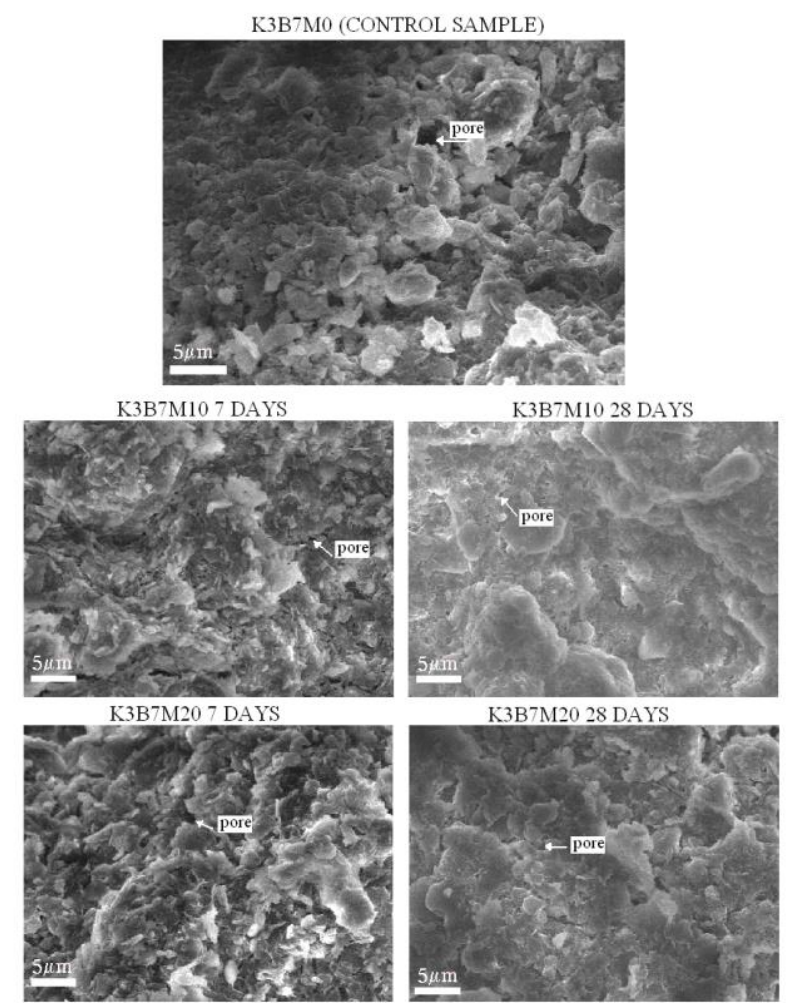

Fig. 7. Control, 7 and 28 days cured $30 \%$ kaolinite $70 \%$ bentonite mixture SEM images (marble dust addition ratios $0,10,20 \%$ )

\section{DISCUSSION}

The addition of marble dust reduced the clay content and an increase in the percentage of the coarser particles. Waste marble dust added to the clay specimens acted also as a filler material, however the performance increase achieved is much more than the added amount because of the pozzolanic reactions [13-14].

The geotechnical properties of the clay samples changed after the treatment with marble dust. The treated clay samples decreased their cohesive properties and behaved as a granular material after curing: swelling percentages reduced, while the shear strength parameters increased as found by other researchers [12-13]. These properties change with curing time, as modification in the microscopic scale continues with the ongoing pozzolanic reaction. SEM images show morphological changes when clay samples are treated with marble dust displaying a more compact structure with less pores, and pores are filled with cementitious products [13]. The small amount of newly formed calcium hydrates due to the pozzolanic reaction could not always be detected by the imaging techniques used, as measurements were realised within a short time of curing. EDS observations represented that with increasing curing time and ongoing pozzolanic reactions new cementitios products occur at the microscale.

This is evident in the EDS results and detailed magnified SEM images (Fig. 10, Fig. 11). If dilution effect was only valid, formation of new minerals would not be observed. Due to the time-dependent pozzolanic reactions, the stabilization of lime soil is a long-term process.
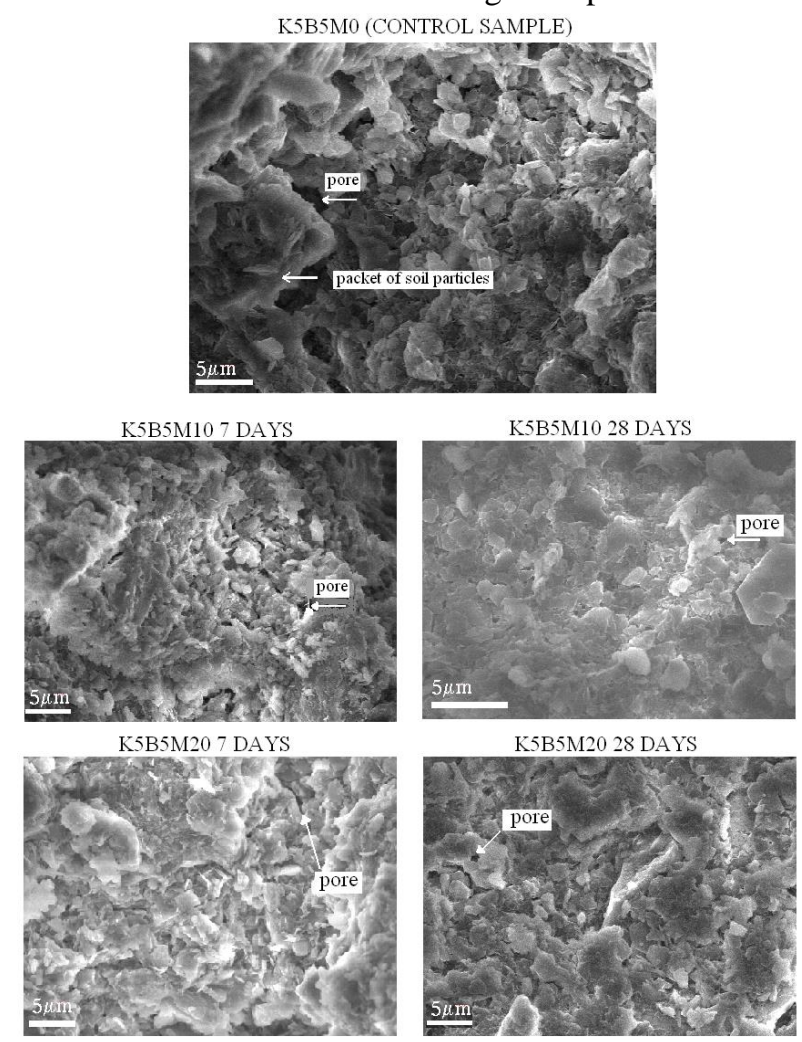

Fig. 8. Control, 7 and 28 days cured $50 \%$ kaolinite $50 \%$ bentonite mixture SEM images

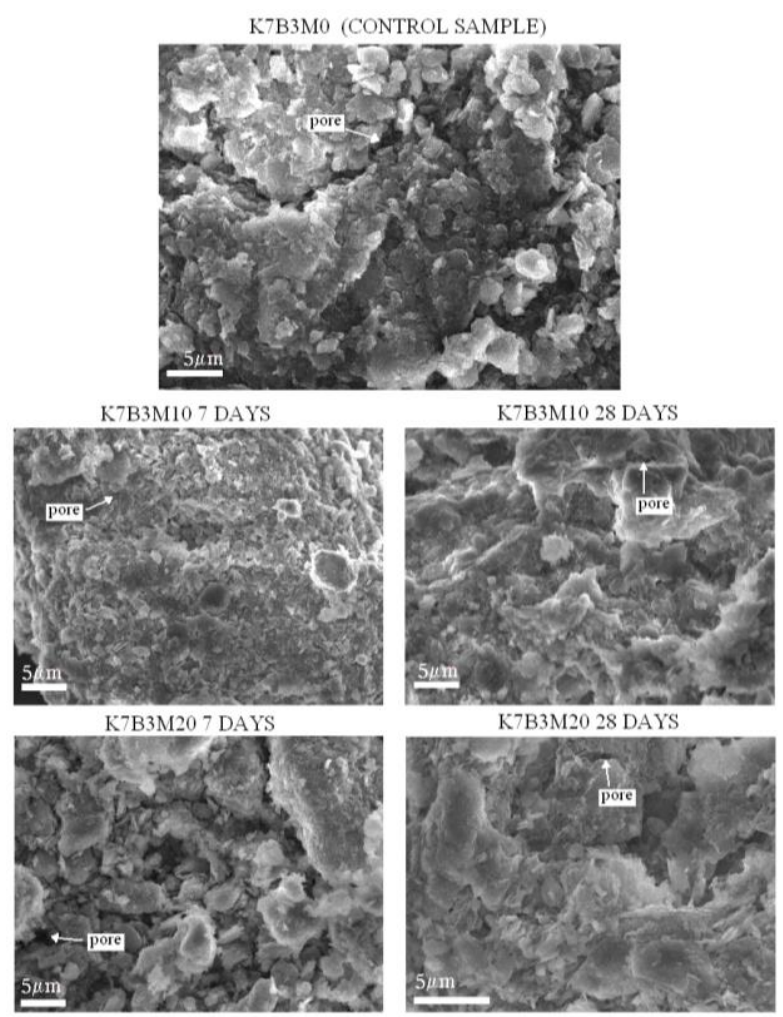

Fig. 9. Control, 7 and 28 days cured $70 \%$ kaolinite $30 \%$ bentonite mixture SEM images

Thus, the unconfined compression and shear strength of the stabilized samples increase while increasing the curing duration. 

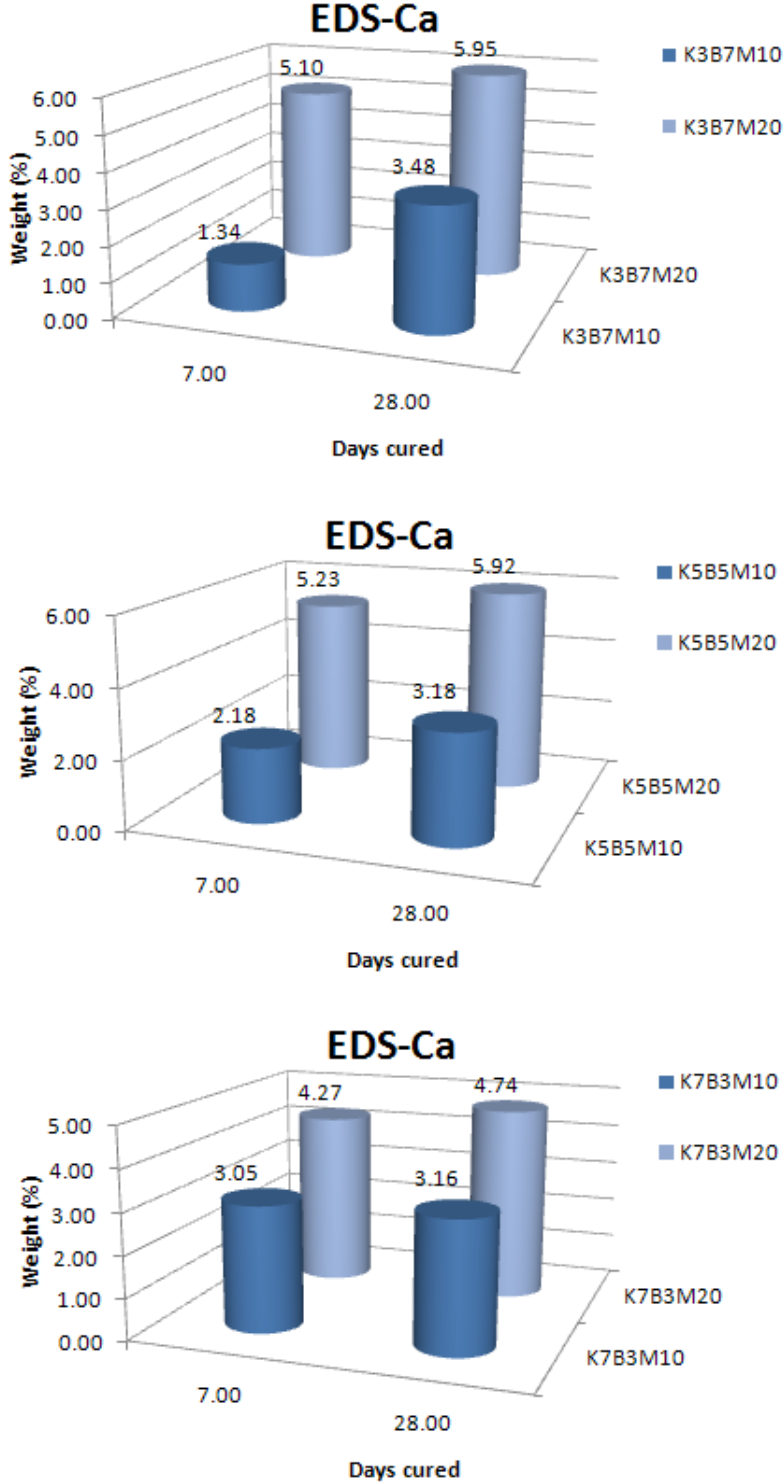

Fig. 10. EDS results of 7 and 28 days cured mixtures

In addition, the formation of the cementitious minerals in marble dust-clay reactions lead to increase in bonding between clay particles. As a result, the strength and the angle of internal friction of the clay samples improved after treatment with waste marble dust.

Aggregation of soil (kaolinite-bentonite mixtures) particles due to marble dust-soil reactions makes pores in the soil matrix smaller and disconnected. As the curing process continues, it becomes very difficult for moisture to enter clay matrix and react with the soil to cause swelling. Furthermore, the cementitious minerals produced contribute to the strong inter-particle bond that can offer the great resistance to swelling of the soil [14]. Thus, increasing the marble dust percentage causes the reduction of swelling of the tested soil specimens.

On conducting an overview of different references and sources dealing with the marble dust stabilized soil, limited amount of the relevant publications were found for comparison with the achieved results in this study.

Publication [7] provides the comparable studies. The swelling percentages of marble dust stabilized clay samples showed up to $50 \%$ performance gain with varying amounts of marble dust addition to the clay specimens. As found in this study, marble dust stabilized clay samples showed lower swelling behavior which causes severe problems in the construction activities.

K7B3M20 28 DAYS

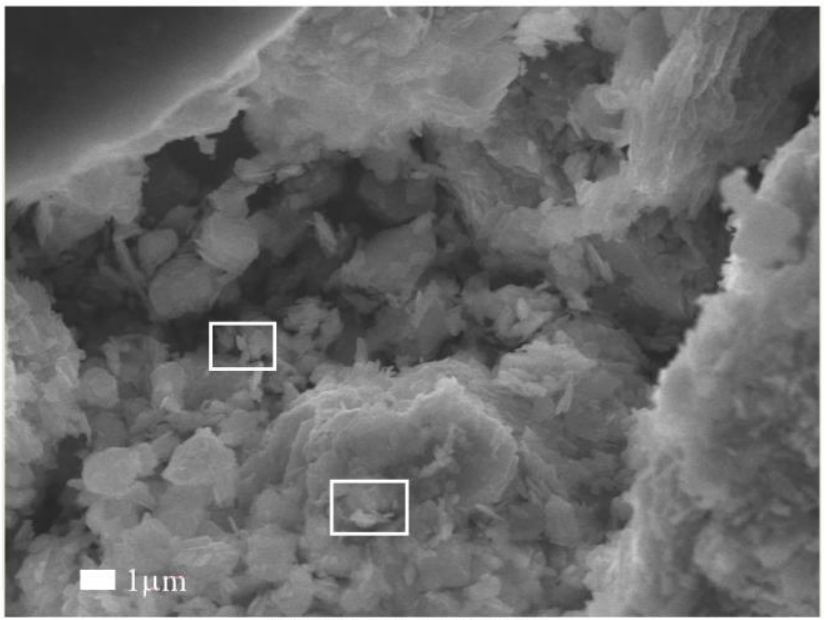

K5B5M20 28 DAYS

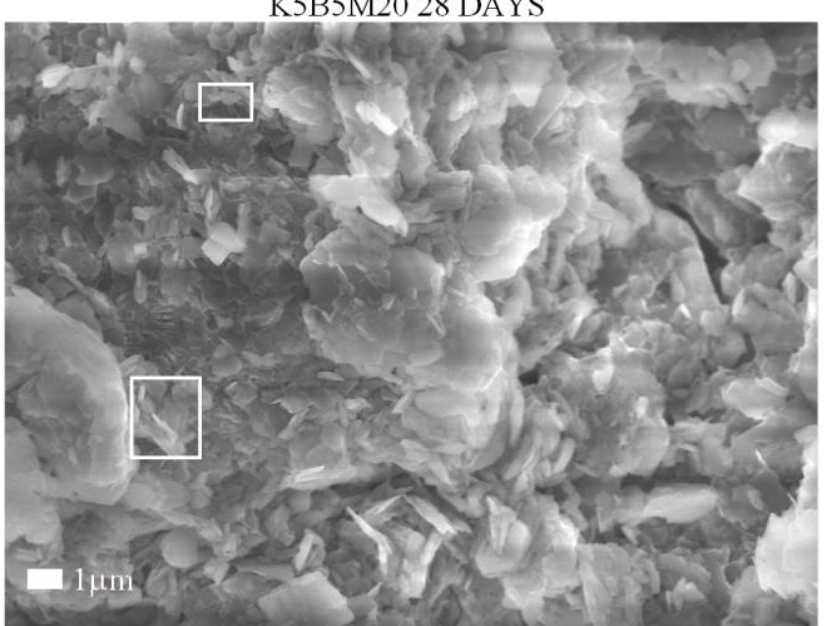

K3B7M20 28 DAYS

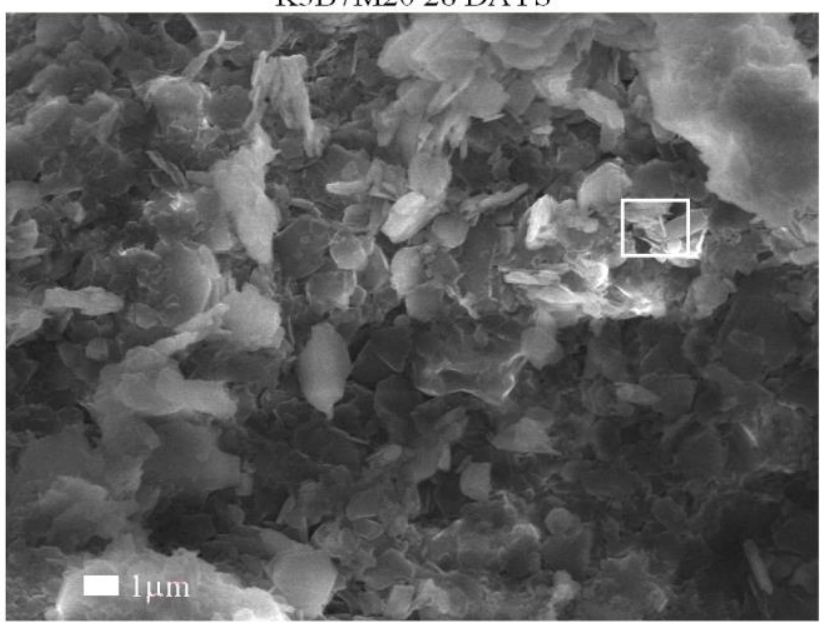

Fig. 11. 28 days cured samples detailed SEM images ( $1 \mu \mathrm{m}$ scale)

Publication [12] provides similar results. Marble dust stabilized clay specimens had a maximum strength gain of 48 per cent in unconfined compression tests compared to untreated clay samples, which is similar to the findings in this work. The highest strength was gained by the soil with the highest clay content.

Publication [13] had also similar findings. The values of the unconfined compressive strength of each fiber-lime 
treated soil specimen, like that of lime-stabilized one, increased while increasing the length of curing. Strength increase was nearly 2 times that of the untreated clay specimen. The internal friction angle values of the specimens tested showed an increase in the length of curing time. In addition, the addition amounts of fiber and lime have significant influence on the development of internal friction angle and the similar trends are found in different curing durations studied as found in this study. Internal friction angle increased 1.2 times with lime addition to the test specimens as described by the authors. The swelling potential of fiber-lime treated specimens, approaching that of lime stabilized one, is far smaller than that of the untreated clay sample. The reduction amount in the swelling is approximately 2 times compared with the untreated specimens.

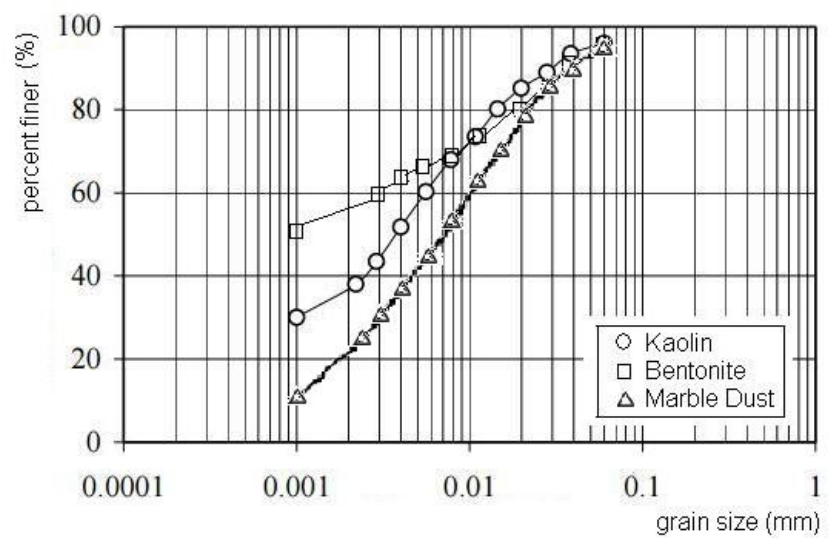

Fig. 12. Particle size distribution of kaolin, bentonite and marble dust specimens

\section{CONCLUSIONS}

The engineering parameters of clay samples having varied activity levels are improved substantially by the addition of waste marble dust. High plasticity samples (K3B7) showed better performance in direct shear and swelling tests, low plasticity samples (K7B3) showed better performance in unconfined compressive strength tests.

All these property changes have their origin in the modification caused by the marble dust-clay reactions in the structure and texture of the treated samples. These properties change with curing time and samples gain performance with the pozzolanic reactions.

Based on the experimental results obtained from this study, finding new utilization areas for waste marble dust (by-product) will decrease environmental pollution and by utilizing these waste materials in problematic soils have great contribution to the economy and conservation of resources. Besides that, usage of waste marble dust in improving problematic soils (especially swelling) will be an alternative and economic method in highly active clayey zones.

\section{Acknowledgments}

The research was supported by the Mugla Sitk1 Kocman University, Turkey, scientific research fund number 12/139.

\section{REFERENCES}

1. Pappu, A., Saxena, M., Asolekar, S.R. Solid Wastes Generation in India and Their Recycling Potential in Building Materials Building and Environment 42 2007: pp. 2311-2320.

2. Karasahin, M., Terzi, S. Evaluation of Marble Waste Dust in the Mixture of Asphaltic Concrete Construction and Building Materials 21 2007: pp. 616-620. http://dx.doi.org/10.1016/j.conbuildmat.2005.12.001

3. Saboya, F., Xavier, G.C., Alexandre, J. The Use of the Powder Marble By-Product to Enhance the Properties of Brick Ceramic Construction and Building Materials 21 2007: pp. 1950-1960.

4. Sarkar, R., Das, S.K., Mandal, P.K., Maiti, H.S. Phase and Microstructure Evolution during Hydrothermal Solidification of Clay-Quartz Mixture with Marble Dust Source of Reactive Lime Journal of the European Ceramic Society 26 2006: pp. 297-304.

5. Acchar, W., Vieira, F.A., Hotza, D. Effect of Marble and Granite Sludge in Clay Materials Materials Science and Engineering A 419 2006: pp. 306-309.

6. Davini, P. Investigation into the Desulphurization Properties of By-Products of the Manufacture of White Marbles of Northern Tuscany Fuel 79 2000: pp. 1363-1369.

7. Zorluer, I., Usta, M. Stabilization of Soils by Waste Marble Dust Proceeding of the fourth national marble symposium, Afyonkarahisar, Turkey 2003: pp. 297-305.

8. Hwang, E. H., Ko, Y. S., Jeon, J. K. Effect of Polymer Cement Modifiers on Mechanical and Physical Properties of Polymer-Modified Mortar Using Recycled Artificial Marble Waste Fine Aggregate Journal of Industrial and Engineering Chemistry 14 2008: pp. 265-271. http://dx.doi.org/10.1016/j.jiec.2007.11.002

9. Karasahin, M., Terzi, S. Evaluation of Marble Waste Dust in the Mixture of Asphaltic Concrete Construction and Building Materials 21 2007: pp. 616-620.

10. Akbulut, H., Gurer, C. Use of Aggregates Produced from Marble Quarry Waste in Asphalt Pavements Building and Environment 42 2007: pp. 1921-1930.

11. Pereira, F.R., Ball, R.J., Rocha, J., Labrincha, J.A., Allen, G.C. New Waste Based Clinkers: Belite and Lime Formulations Cement and Concrete Research 38 2008: pp. $511-521$. http://dx.doi.org/10.1016/j.cemconres.2007.11.008

12. Okagbue, C.O., Onyeobi, T.U.S. Potential of Marble Dust to Stabilise Red Tropical Soils for Road Construction Engineering Geology 53 1999: pp. 371-380.

13. Cai, Y., Shi, B., Ng, C.W.W., Tang, C. Effect of Polypropylene Fibre and Lime Admixture on Engineering Properties of Clayey Soil Engineering Geology 87 2006: pp. 230-240.

14. Al-Mukhtar, M., Khattab, S., Alcover, J.F. Microstructure and Geotechnical Properties of Lime-Treated Expansive Clayey Soil Engineering Geology 139 2012: pp. 17-27. http://dx.doi.org/10.1016/j.enggeo.2012.04.004 